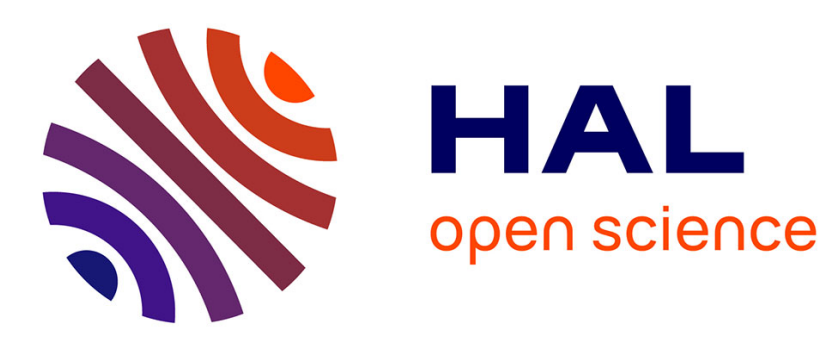

\title{
LED-pumped femtosecond Cr:LiSAF regenerative amplifier system
}

Hussein Taleb, P. Pichon, Frédéric Druon, François Balembois, Patrick

Georges

\section{- To cite this version:}

Hussein Taleb, P. Pichon, Frédéric Druon, François Balembois, Patrick Georges. LED-pumped femtosecond Cr:LiSAF regenerative amplifier system. Optics Letters, 2021, 46 (10), pp.2421. 10.1364/OL.424313 . hal-03272685

\section{HAL Id: hal-03272685 \\ https://hal.science/hal-03272685}

Submitted on 19 Jul 2021

HAL is a multi-disciplinary open access archive for the deposit and dissemination of scientific research documents, whether they are published or not. The documents may come from teaching and research institutions in France or abroad, or from public or private research centers.
L'archive ouverte pluridisciplinaire HAL, est destinée au dépôt et à la diffusion de documents scientifiques de niveau recherche, publiés ou non, émanant des établissements d'enseignement et de recherche français ou étrangers, des laboratoires publics ou privés. 


\title{
LED-pumped femtosecond Cr:LiSAF regenerative amplifier system
}

\author{
Hussein Taleb ${ }^{1, *}$, Pierre Pichon ${ }^{1}$, Frederic Druon ${ }^{1}$, François Balembois ${ }^{1}$ \\ AND PATRICK GEORGES ${ }^{1}$. \\ ${ }^{1}$ Université Paris-Saclay, Institut d'Optique Graduate School, CNRS, Laboratoire Charles Fabry, 91127, Palaiseau, France \\ *Corresponding author: hussein.taleb@institutoptique.fr
}

Received XX Month XXXX; revised XX Month, XXXX; accepted XX Month XXXX; posted XX Month XXXX (Doc. ID XXXXX); published XX Month XXXX

\begin{abstract}
We report on the first LED-pumped femtosecond regenerative amplifier. It is based on a Cr:LiSAF crystal pumped by 2240 blue LEDs via a Ce:YAG luminescent concentrator. The amplifier was seeded by pulses from a Ti:sapphire oscillator at $835 \mathrm{~nm}$ temporally stretched from 90 fs to 100 ps. At the output of the regenerative amplifier, we obtain $1 \mathrm{~mJ}$ pulse energy at a $10 \mathrm{~Hz}$ repetition rate, given by the frequency of the LED pumping module. After compression, we obtain 100-fs pulses with a spectral bandwidth of $10 \mathrm{~nm}$ at $835 \mathrm{~nm}$. (C) 2021 Optical Society of America
\end{abstract}

OCIS codes: (140.7090) Ultrafast lasers; (140.3280) Laser amplifiers; (160.6990) Transition-metal-doped materials; (230.3670); Light-emitting diodes; (140.5560) Pumping.

http://dx.doi.org/10.1364/OL.99.099999

During the last two decades, LEDs have seen a dramatic improvement of their performance and a drastic cost reduction, making them one of the most efficient and affordable lighting sources. Combined with luminescent concentrators [1], they allow to reach irradiances up to $10 \mathrm{~kW} / \mathrm{cm}^{2}$ [2], more than one order of magnitude higher than LEDs. Pumped by blue LEDs, Ce:YAG concentrators [3] and Ce:LuAG concentrators [2] provide high brightness $100 \mathrm{~mJ}$-class-sources between $530 \mathrm{~nm}$ and $650 \mathrm{~nm}$, right in the "yellow gap" where semiconductors are less efficient than in other wavelength ranges (like blue or near infrared). This offers new opportunities for pumping broadband laser materials from the transition metal ion family, since their absorption band is close to the yellow gap. Ti:sapphire, alexandrite or Cr:LiSAF are part of this category. Compared to other pump sources, LEDpumped luminescent concentrators combine a unique set of properties: as rugged and cost effective as flashlamps, as stable, long-lifetime and reliable as semiconductors. In addition, their complexity is much less than frequency-doubled Nd:doped green laser often used for Ti:sapphire pumping.

Laser performances of Ti:sapphire [2], alexandrite [4] and Cr:LiSAF [5] have recently been investigated under LED-pumping showing a broad tunability in the near infrared, essential for femtosecond lasers. Therefore, LED-pumped luminescent concentrators open the road to new femtosecond laser systems.

LED-pumped luminescent concentrators have their best performance in quasi-continuous-wave at low repetition rate, a regime where LEDs can be driven far above their nominal power specified in continuous-wave (3-4 times higher for pulse durations in the $\mu$ s range). At low repetition rates, the concentrators do not require specific cooling that could affect its reflective properties based on total internal reflections. These characteristics push us to consider pulsed amplifiers (often pumped in pulsed regime) instead of mode-locked oscillators (generally pumped in $\mathrm{CW}$ ) for a LED-pumped crystal inserted in a femtosecond laser chain. Moreover, we believe that one of the main interests of LEDpumping for femtosecond systems is access to high pulse energy at a low cost. We therefore focus this demonstration on an amplifier system.

Our previous works demonstrate that Cr:LiSAF has a gain above Ti:sapphire and alexandrite under similar LED-pumping conditions with Ce-doped concentrators. This is the reason why we select Cr:LiSAF in order to build the first LED-pumped femtosecond regenerative amplifier presented in this paper.

An overview of the experimental setup is presented in Fig. 1, in a chirped pulse amplification configuration (CPA). A mode-locked femtosecond Ti:sapphire oscillator (Mai Tai from Spectra-Physics) produces infrared seed-pulses at a repetition rate of $80 \mathrm{MHz}$, centered at $835 \mathrm{~nm}$ with a full width at half maximum (FWHM) spectral bandwidth of $10 \mathrm{~nm}$. Assuming a sech ${ }^{2}$ temporal profile, the pulse duration is measured to be approximately $90 \mathrm{fs}$ at FWHM. These pulses are temporally stretched up to $100 \mathrm{ps}$ in an Offner type stretcher using two concave and convex mirrors (silver coating of up to $96 \%$ reflectivity at $835 \mathrm{~nm}$ ) and a diffraction grating (1400 lines/mm, gold coating). The stretched pulses (with an energy of $1.25 \mathrm{~nJ}$ ) are sent to the LED-pumped Cr:LiSAF regenerative amplifier described in the following. To ensure an efficient pulse injection in the amplifier, the waist radius is adjusted to match the cavity mode of the amplifier, using a two-lens afocal system (with focal lengths of $750 \mathrm{~mm}$ and $400 \mathrm{~mm}$ ) placed between the stretcher and the amplifier. In the last part of the setup, the pulses are recompressed with two reflective diffraction gratings (1480 lines/mm, gold coating). 


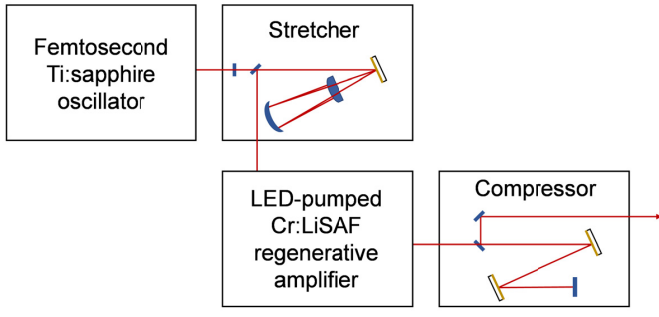

Fig. 1. Schematic of the chirped pulse amplification using a Cr:LiSAF regenerative amplifier. The oscillator produces $90 \mathrm{fs}$ pulses at $835 \mathrm{~nm}$. The Cr:LiSAF regenerative amplifier is pumped by LEDs and operates at $10 \mathrm{~Hz}$. The pulses are temporally stretched (up to $100 \mathrm{ps}$ ) and recompressed using grating-based pulse stretcher and compressor.

The pumping module (Fig. 2) consists in a $1.6 \times 10^{19} \mathrm{~cm}^{-3}$-doped Ce:YAG luminescent concentrator $(14 \mathrm{~mm} \times 200 \mathrm{~mm} \times 1 \mathrm{~mm})$ composed of two slabs $(14 \mathrm{~mm} \times 100 \mathrm{~mm} \times 1 \mathrm{~mm})$ bonded together with a UV-curing optical adhesive. 2240 blue LEDs (LUXEON Z Royal blue from Lumileds) with an emission spectrum centered at $450 \mathrm{~nm}$ are placed close to the two large facets of the luminescent concentrator (1120 LEDs on each $14 \mathrm{~mm} \times 200 \mathrm{~mm}$ facet). Blue light is absorbed by the $\mathrm{Ce}^{3+}$ ions, reemitted within the Ce:YAG, and guided via total internal reflections toward the small facets $(1 \mathrm{~mm} \times 14 \mathrm{~mm})$. A detailed description of the pumping module is presented in [5].

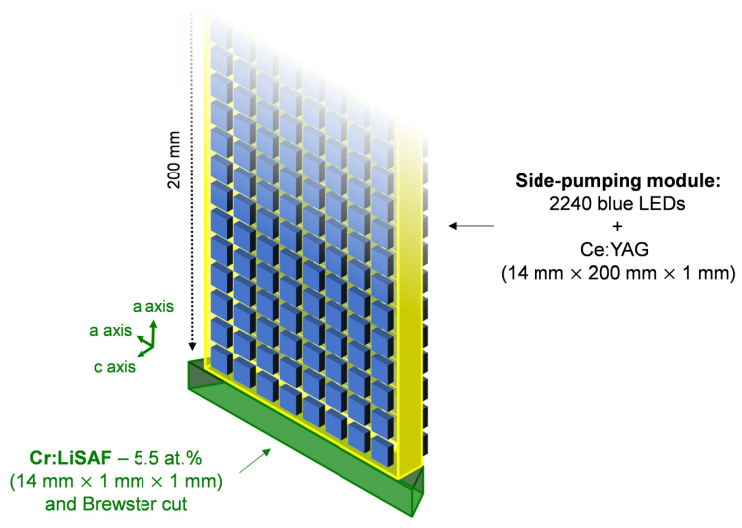

Fig. 2. LED-pumped Cr:LiSAF crystal via a Ce:YAG luminescent concentrator.

A 5.5\% doped Cr:LiSAF crystal is bonded to one of the small facets of the Ce:YAG luminescent concentrator with a UV-curing optical adhesive (Fig. 2). The Cr:LiSAF is Brewster-angle cut and its dimensions $(14 \mathrm{~mm} \times 1 \mathrm{~mm} \times 1 \mathrm{~mm})$ are designed to match the Ce:YAG small facet. On the opposite small facet of the luminescent concentrator, a plane mirror is placed to recycle part of the light that goes in the opposite direction. LEDs are driven in a pulsed regime at $10 \mathrm{~Hz}$ to reduce thermal effects observed in the Cr:LiSAF, with a maximum current of $5 \mathrm{~A}$. The LED pulse duration is optimized by monitoring the fluorescence signal of the Cr:LiSAF and fixed at $100 \mu \mathrm{s}$, corresponding to a temperature of $39^{\circ} \mathrm{C}$. Beyond this value, the fluorescence signal starts to decrease, due to thermal quenching of fluorescence [6-8]. With such a pulse duration, the luminescent concentrator provides an energy of $103 \mathrm{~mJ}$ used to pump the Cr:LiSAF crystal, with an irradiance of $7.3 \mathrm{~kW} / \mathrm{cm}^{2}$ at $10 \mathrm{~Hz}$. The emission spectrum of Ce:YAG is in the range $520-640 \mathrm{~nm}$, with a mean wavelength at $580 \mathrm{~nm}$. This corresponds to the short wavelength tail of the Cr:LiSAF absorption band peaking at $670 \mathrm{~nm}$ [9]. Based on the overlap between the absorption cross section of the Cr:LiSAF and the emission spectrum of the Ce:YAG, we estimate that an energy of 32 $\mathrm{mJ}$ is absorbed in the Cr:LiSAF crystal.

The experimental setup of the LED-pumped Cr:LiSAF regenerative cavity is shown in Fig. 3. The LED-pumped Cr:LiSAF crystal shown in Fig. 2 is inserted in a 3-mirrors cavity. In order to take benefit of the strong absorption of the Cr:LiSAF on the c-axis, the pumping module is oriented in the vertical plane, perpendicular to the plane of the cavity. Two concave mirrors M1 $(\mathrm{RoC}=0.5 \mathrm{~m})$ and $\mathrm{M} 2(\mathrm{RoC}=1 \mathrm{~m})$ are placed at half their radii of curvature from the Cr:LiSAF crystal. In this configuration, the waist radius in the Cr:LiSAF crystal is $260 \mu \mathrm{m}$. This corresponds to the largest radius that does not cause diffraction losses [10] because of the aperture of $1 \times 1 \mathrm{~mm}^{2}$. Considering the size of the laser beam, the pump duration, and the Cr:LiSAF lifetime, we can estimate an accessible stored energy of $3.1 \mathrm{~mJ}$. In the second part of the cavity, between M2 and M3 (plane), we insert a KDP Pockels cell (QX1020, Gooch \& Housego, with a rise and fall time of $3 \mathrm{~ns}$ ) and a polarizer (98\% transmission for the horizontal polarization and $80 \%$ reflection for the vertical one). The distance of $0.5 \mathrm{~m}$ between M2 and M3 ensures that the small beam divergence is adapted to operate with a Pockels cell and fixes the beam radius at $470 \mu \mathrm{m}$. In this configuration, the cavity length is $1.27 \mathrm{~m}$ corresponding to a cavity roundtrip time of $8.5 \mathrm{~ns}$. We use a Faraday rotator combined with a half-wave plate and a polarizer to separate the input and the output of the amplifier.

After 34 cavity roundtrips, corresponding to a buildup time of 290 ns, the pulse reaches its maximum energy (Fig. 4(a)). The Pockels cell switches the polarization, forcing the pulse to be ejected from the cavity by the intracavity polarizer (Fig. 4(b)). After the second polarizer, the measured output pulse energy is $1 \mathrm{~mJ}$. This corresponds to an extraction efficiency of $32 \%$. One can note that the maximum fluence on the Cr:LiSAF is $0.47 \mathrm{~J} / \mathrm{cm}^{2}$, which is safe compared to the damage threshold. We can see a small peak

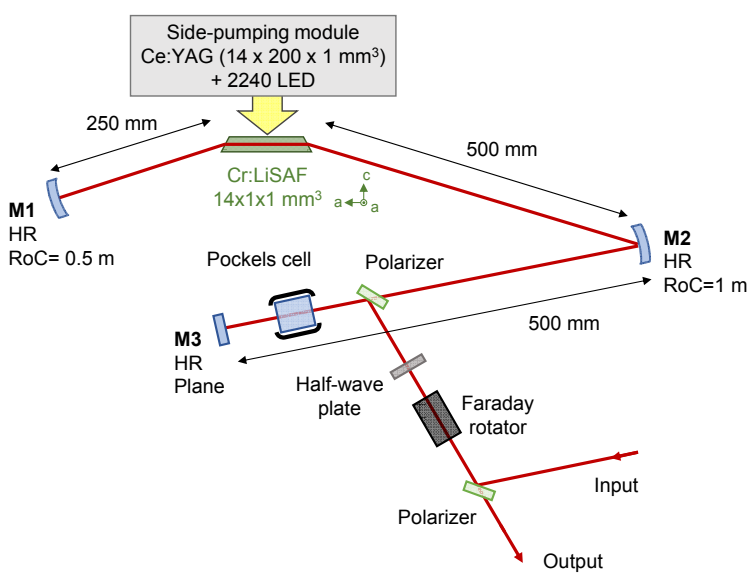

Fig. 3. Experimental setup of the LED-pumped Cr:LiSAF regenerative amplifier. 


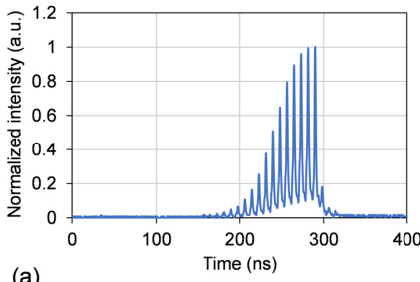

(a)

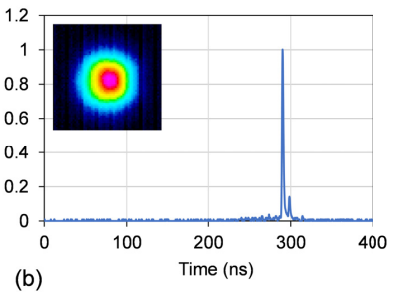

Fig. 4. a) Evolution of the intracavity pulse during the amplification. The buildup time is $290 \mathrm{~ns}$. b) Output pulse after ejection. Inset: beam profile of the amplified pulses.

$(\approx 10 \%)$ after the ejection of the main pulse. This can be attributed to the residual transmission of the intracavity polarizer in the vertical polarization.

Based on the Frantz-Nodvik equation [11], considering a saturation fluence of $4.68 \mathrm{~J} / \mathrm{cm}^{2}$ at $835 \mathrm{~nm}$ for the Cr:LiSAF and given the experimental energy and buildup time, the double-pass small signal gain is estimated to be $\mathrm{G}_{0}=1.8$, with an overall loss of the regenerative amplifier cavity at $8 \%$ per roundtrip. The output beam profile is shown in the inset of Fig. 4(b), close to a TEM 00 profile. We measure a beam quality $\mathrm{M}^{2}$ of 1.26 in the vertical plane and 1.21 in the horizontal plane. At the output of the regenerative amplifier, we measure a beam pointing stability of $2.26 \mu \mathrm{rad}$ RMS over 1000 shots.

The amplified pulses are then sent to the compressor (designed for a femtosecond Ti:sapphire chain at $800 \mathrm{~nm}$ ). After compression, we obtain a pulse energy of $0.3 \mathrm{~mJ}$, limited by the non-optimized efficiency of the compressor of $30 \%$ at the operating wavelength. The spectrum of the compressed pulses is centered at $835 \mathrm{~nm}$ and is not distorted or narrowed by the amplification process (Fig. 5). The compressor is aligned for maximal compression to compensate for the pulse stretcher and for the group velocity dispersion of the regenerative amplifier cavity, mainly due to the Pockels cell and to the Cr:LiSAF crystal. Inset of Fig. 5 shows the autocorrelation trace of the compressed pulses, measured using a single-shot autocorrelator. We measure

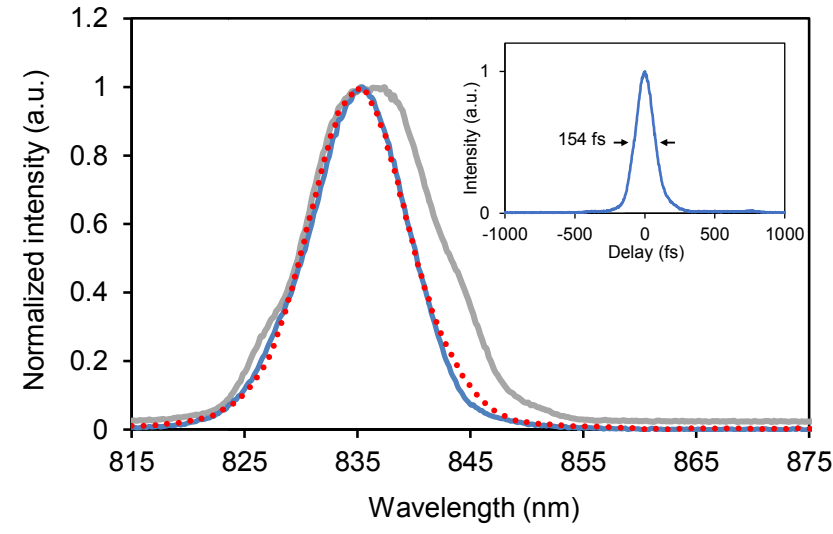

Fig. 5. Spectra of the seed pulses (dotted red curve) and the compressed pulses (solid blue curve). Spectrum of the free running cavity-dumped amplifier (solid grey curve). Inset: Single-shot autocorrelation trace of the compressed pulses. The FWHM is $154 \mathrm{fs}$, corresponding to a pulse duration of $100 \mathrm{fs}$. an autocorrelation duration of $154 \mathrm{fs}$ at FWHM, corresponding to $100 \mathrm{fs}$ pulse duration assuming a sech ${ }^{2}$ temporal profile. This pulse duration along with a spectral bandwidth of $10 \mathrm{~nm}$, yields a timebandwidth product of 0.43 . Since the pulse spectrum does not significantly evolve with the amplification, the temporal augmentation suggests the existence of a residual phase that has not been compensated. The pulse compression could be then improved by further optimization of the high-order phases.

We then investigate the spectral tunability of the Cr:LiSAF regenerative amplifier. For the sake of the system agility, we decide to vary only the wavelength of the oscillator without any other realignment, leaving the stretcher and amplifier unchanged during the measurements. Fig. 6 shows the variation of the amplified pulse energy and buildup time with the wavelength. A maximum energy of $1 \mathrm{~mJ}$ is obtained between $835 \mathrm{~nm}$ and $845 \mathrm{~nm}$, which corresponds to the central wavelength of the free running $\mathrm{Cr}$ :LiSAF regenerative amplifier (Fig. 5). The tuning range $(820-875 \mathrm{~nm})$ is limited by the aperture of the diffraction grating used in the pulse stretcher. At the edges of the tuning range, the pulse energy remains over $0.5 \mathrm{~mJ}$ with less than $25 \%$ buildup time increase. This shows that the limitation is coming from the stretcher and not from the Cr:LiSAF bandwidth since much broader tunability has been demonstrated under LED-pumping in quasi-continuous wave operation [5].

It is worth noting that no distortion or narrowing is observed on the spectrum after amplification, on the range between $825 \mathrm{~nm}$

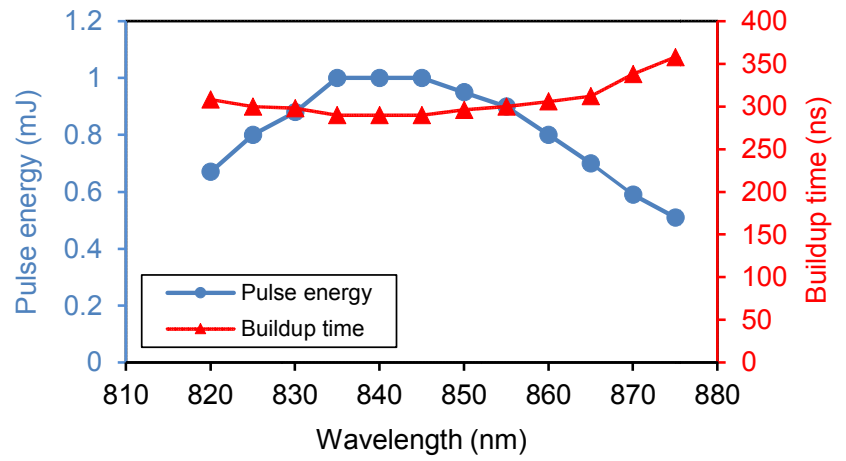

Fig. 6. Amplified pulse energy and buildup time as a function of wavelength for the LED-pumped Cr:LiSAF regenerative amplifier.

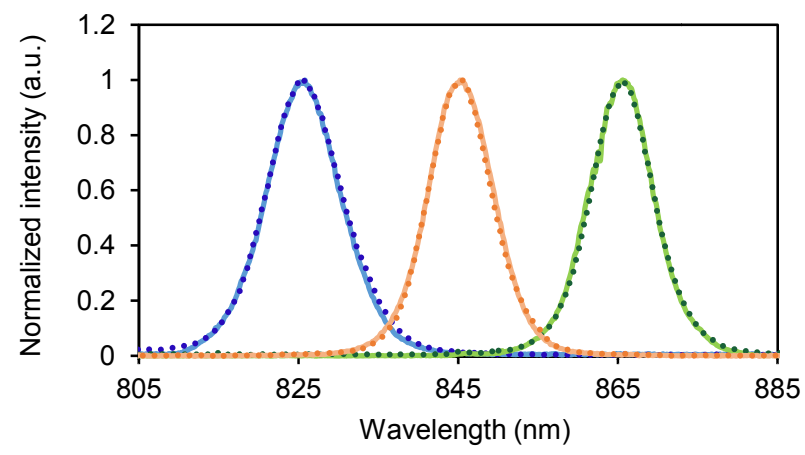

Fig. 7. Spectra of the seed pulses (dotted curves) and the amplified pulses (solid curves) between $825 \mathrm{~nm}$ and $865 \mathrm{~nm}$. 
and $865 \mathrm{~nm}$ (Fig. 7). This means that Cr:LiSAF could allow the amplification of pulses much shorter than $100 \mathrm{fs}$ and that, in our case, we are limited by the oscillator duration.

Cr:LiSAF femtosecond regenerative amplifiers have been reported previously. They can be sorted in two categories depending on the pump source. Under CW pumping, with gas lasers $[12,13]$ or laser diodes $[13,14]$, the reported performances are $\mu \mathrm{J}$ pulses at $\mathrm{kHz}$ repetition rates. The best performance to date was reported in [15] with $10 \mu \mathrm{J}$ pulses at $6 \mathrm{kHz}$ compressed to $170 \mathrm{fs}$. Diode-pumped setups are advantageous for high repetition rates but exhibit relatively low small-signal gains: typically below 1.1 per roundtrip. This induces a large buildup time around $1 \mu \mathrm{s}$ [13-15] corresponding to approximately 200 roundtrips [15]. The second category is flashlamp-pumped [16-18]. These setups are well suited to produce high pulse energy: in the mJ range and up to $15 \mathrm{~mJ}$ [18]. Moreover, the small-signal-gain is much higher, leading to 35 roundtrips typically. However, the repetition rates are $1 \mathrm{~Hz}$ $[17,18]$ or a few $\mathrm{Hz}(6 \mathrm{~Hz})[16]$, limited by the flashlamp lifetime and by thermal issues in the Cr:LiSAF rods. The pulse durations after compression in these setups are around $100 \mathrm{fs}$. The difference in pulse duration between diode and flashlamppumping configurations can be attributed to the spectral gain narrowing that depends on the number of roundtrips. The performances reported here in terms of gain, buildup time, output energy, and pulse duration are close to the flashlamp-pumped Cr:LiSAF regenerative amplifiers.

However, the potential of LED-pumped regenerative amplifiers is far beyond the flashlamp-pumped amplifiers. The lifetime of the pump source is much longer, thanks to the redundancy offered by thousands of LEDs in the setup and to the robustness of Ce:YAG. The repetition rate of $10 \mathrm{~Hz}$ is already higher than in flashlamppumped Cr:LiSAF regenerative amplifiers previously demonstrated and can be further increased. LED-pumped luminescent concentrators can operate at repetition rates up to $200 \mathrm{~Hz}$ without deleterious effect on the performance of the pump energy, thanks to the excellent thermo-optical properties of Ce:YAG [19]. In our setup, the repetition rate is currently limited by the heating of the Cr:LiSAF crystal due to the absence of adequate cooling. Thermal management of the heat generated in the Cr:LiSAF could be greatly improved by a better mechanical contact with a well-designed heat sink.

The results in terms of free running spectrum and tunability indicate that the LED-pumped Cr:LiSAF amplifier can be used for pulses with a larger spectral bandwidth, leading to shorter pulse durations around $70 \mathrm{fs}$. In addition, energy scaling could be easily achieved since LEDs are low cost devices and Ce:YAG luminescent concentrators with larger sizes are available.

In conclusion, we demonstrate the first LED-pumped femtosecond amplifier. It includes a Cr:LiSAF crystal. The performances of the presented system are in line with previously reported results of flashlamp-pumped regenerative amplifiers, but with semiconductor-base-pumping reliability. This represents the first step, and we expect a wide potential for improvement, including the increase of the repetition rate, the reduction of the pulse duration and above all, the energy scaling. We believe that this work opens the route to a new generation of compact ultrashort laser sources operating in the 10 -to- $100 \mathrm{~Hz}$ range with sub-100-fs pulses and energies in the $10 \mathrm{~mJ}$ range.
Acknowledgements. The authors acknowledge the help of Catherine Le Blanc (Laboratoire LULI Ecole Polytechnique) with her technical support and helpful discussions. The authors thank Jean-Philippe Rousseau (Laboratoire d'Optique Appliquée) for the loan of the gratings for the pulse compressor.

Funding. Agence Nationale de la Recherche and Direction Générale de l'Armement (ANR-17-ASTR-0021).

Disclosures. The authors declare no conflicts of interest.

Data availability. Data underlying the results presented in this paper are not publicly available at this time but may be obtained from the authors upon reasonable request.

\section{REFERENCES}

1. A. Barbet, A. Paul, T. Gallinelli, F. Balembois, J.-P. Blanchot, S. Forget, S. Chénais, F. Druon, and P. Georges, Optica 3, 465 (2016).

2. P. Pichon, A.Barbet, J.-P. Blanchot, F.Druon, F. Balembois, and P. Georges, Optica 5, 1236 (2018).

3. P. Pichon, A. Barbet, D. Blengino, P. Legavre, T. Gallinelli, F. Druon, J.P. Blanchot, F. Balembois, S. Forget, S. Chenais, and P. Georges, Opt. Laser Technol. 96, 7 (2017).

4. P. Pichon, A. Barbet, F. Druon, J.-P. Blanchot, F. Balembois, and P. Georges, Opt. Lett. 42, 4191 (2017).

5. P. Pichon, F. Druon, J.-P. Blanchot, F. Balembois, and P. Georges, Opt. Lett. 43, 4489 (2018).

6. M. Stalder, M. Bass, and B.H.T. Chai, J. Opt. Soc. Amer. B 9, 2271 (1992).

7. F. Falcoz, F. Druon, F. Balembois, F. Kerboull, P. Georges, and A. Brun, Opt. Lett. 21, 1253 (1996).

8. F. Balembois, F. Kerboull, F. Druon, F. Falcoz, P. Georges, and A. Brun, IEEE J. Quantum Electron. 33, 1614 (1997).

9. S. A. Payne, L. L. Chase, L. K. Smith, W. L. Kway, and H. W. Newkirk, Journal of Applied Physics 66, 1051 (1989).

10. P. Pichon, H. Taleb, F. Druon, J.-P. Blanchot, P. Georges and F. Balembois, Opt. Express 27, 23446 (2019).

11. L.M. Frantz, and J.S. Nodvik, J. Appl. Phys. 34, 2346 (1963).

12. F. Balembois, P. Georges, F. Salin and A. Brun, Opt. Lett. 18, 1250 (1993).

13. S. C. W. Hyde, N. P. Barry, R. Mellish, P. M. W. French, and J. R. Taylor, Opt. Lett. 20, 160 (1995).

14. R. Mellish, S.C.W. Hyde, N.P. Barry, R. Jones, P.M.W. French1, J.R. Taylor, C.J. van der Poel, and A. Valster, Appl. Phys. B 65, 221 (1997).

15. A. Isemann, P. Weßels, C. Fallnich, Opt. Commun. 260, 211 (2006).

16. P. Beaud, E. Miesak, Y-F. Chen, B.H.T. Chai and M.C. Richardson, Opt. Commun. 95, 46 (1993).

17. P. Beaud, M. Richardson, E. J. Miesak, and B. H. T. Chai, Opt. Lett. 18, 1550 (1993).

18. T. Ditmire, H. Nguyen, and M. D. Perry, J. Opt. Soc. Am. B 11, 580 (1994).

19. S. Arjoca, E. G Víllora, D. Inomata, K. Aoki, Y. Sugahara, and K. Shimamura, Mater. Res. Express 2, 055503 (2015). 